\title{
Mandatory HIV testing as a prerequisite for surgical procedures: Perspectives on rights and ethics
}

\author{
B N Joseph, ' B Pharm, MSc, FPCPharm; A M Jamil,' BPharm; B M Aya, ${ }^{2}$ BPharm; A I Yahya, ${ }^{3}$ MBBS; \\ D A Dangiwa, ${ }^{1}$ BPharm, PharmD, MPharm, FPCPharm; D N Jangkam, ${ }^{4}$ LLB, MLL, PhD; M L P Dapar, ${ }^{1}$ BPharm, MSc, PhD, FPCPharm \\ ${ }^{1}$ Department of Clinical Pharmacy and Pharmacy Practice, Faculty of Pharmaceutical Sciences, University of Jos, Nigeria \\ 2 Pharmacy Department, Federal Medical Centre, Keffi, Nigeria \\ ${ }^{3}$ Department of Ear, Nose and Throat, Federal Teaching Hospital, Gombe, Nigeria \\ ${ }^{4}$ Faculty of Law, University of Jos, Nigeria
}

Correspondence: B N Joseph (jbnasara2002@yahoo.com)

\begin{abstract}
Background. Undergoing mandatory HIV testing as a criterion for a surgical or invasive procedure is illegal in Nigeria, and unethical. This includes requesting an HIV test without the consent of the client, and the disclosure of the test results.

Objectives. To assess the practice of mandatory HIV testing among health practitioners, and to examine HIV testing without consent, and the disclosure of test results to the patient.

Methods. This was a cross-sectional survey of both medical doctors and nurses with surgical skills. We used convenience sampling to select respondents from Jos University Teaching Hospital, Nigeria and Federal Teaching Hospital, Gombe, Nigeria. A total of 99 respondents filled and returned a questionnaire. Statistical Package for the Social Sciences version 20 was used to manage the data, and the results were presented using descriptive statistics.

Results. Over one-third (34.3\%) of the respondents reported that they would insist on seeing an HIV test result before performing a surgical or invasive procedure; meanwhile, 4 (4\%) of the respondents had refused to render surgical or invasive intervention to HIV clients, while (3\%) admitted having refused surgical procedures to patients who refused to take an HIV test. The majority of the respondents (79; 79.8\%) reported that the basic equipment and consumables needed for universal precautions were either not available or grossly inadequate.

Conclusion. Requests for patients to take an HIV test before surgical procedures are frequent; however, only a few respondents had ever refused to provide a surgical intervention on the basis of a patient's HIV-positive status. Equipment and consumables necessary for universal precautions were either not available or grossly inadequate in the surveyed hospitals.
\end{abstract}

S Afr J Bioethics Law 2018;11(2):70-74. DOI:10.7196/SAJBL.2018.v11i2.636

HIV is a complex and multifaceted entity, especially in terms of the biopsychosocial model of disease. For decades, its biological characteristics have consistently outstripped our human ability to understand its molecular and pathogenic complexities. The psychosocial, legal and ethical implications are equally devastating, requiring concerted global debates and commitments on the subject of human rights. While the Universal Declaration of Human Rights (UDHR) was adopted as an instrument that guarantees and safeguards the inherent dignity and equality of every being, and as a framework for bettering the relationship between a government and its citizenry, the translation of the declaration into practical law, and its subsequent implementation, has suffered continual debates, hitches and neglect worldwide. ${ }^{[1]}$ To what extent has Nigeria implemented policies protecting any of the 'rights' it purports to defend? It is evident that in Nigeria, HIV-positive people are denied employment and even access to healthcare on the basis of stigmatisation. ${ }^{[2]}$

Mandatory HIV testing as a prerequisite for surgery, and even worse, the refusal of treatment to patients infected with the virus, is ethically unacceptable worldwide. ${ }^{[3]}$ In India, such practice was criticised and said to have no public health justification, as it has the potential to drive vulnerable and possibly HIV-positive people out of HIV/AIDS intervention programmes. ${ }^{[4]}$ Thomas ${ }^{[3]}$ showed that even when the government had issued guidelines in compliance with the UDHR charter, they were rarely enforced, resulting in the widespread practice of mandatory HIV testing, with practitioners maintaining that the risk of transmission is not zero, despite universal precautions.

While surgeons could argue the case on the basis of their risk of infection, mandatory testing leads to stigmatisation and discrimination. Conversely, in the developed world, many clients treat infected health practitioners with distrust, a situation that led the American College of Surgeons (ACS) to release a guideline to resolve the stalemate. ${ }^{[5]}$

This study assessed the practice of mandatory HIV testing, HIV testing without consent and disclosure of test results in Nigeria.

\section{Methods}

\section{Study setting and design}

The study was carried out at Federal Teaching Hospital, Gombe, Nigeria and Jos University Teaching Hospital (JUTH), Nigeria. It was a cross-sectional descriptive survey of both medical doctors and nurses trained and engaged in surgical procedures. 


\section{Participants, sampling procedure and data- collection instrument}

We used convenience sampling to select study participants. Respondents who satisfied the selection criteria filled and returned our questionnaires. The questionnaires were administered directly to the participants during clinical meetings in the hospital. The study was conducted in the months of February and March 2017. The first section of the questionnaire ascertained the demographic characteristics of respondents; the second probed the attitude of respondents towards people living with HIV/AIDS (PLWHA), using a 4-item Likert scale, with reverse scoring. The maximum score obtainable was 16 and the minimum 4; respondents achieving scores $\leq 7$ were said to have a positive attitude, while a score $\geq 8$ was defined as expressing a negative attitude. The third aspect of the questionnaire involved yes or no questions designed to assess the attitude and practice of respondents towards mandatory HIV testing, while the fourth domain measured respondents' knowledge about HIV transmission. Five Likert-scale questions with four response options (strongly agree, agree, disagree and strongly disagree) were asked. The maximum score attainable was 20 , and the minimum 5 . A score $\leq 9$ was defined as low, $10-15$ as moderate and $16-20$ as high. We sought the views and experiences of respondents on universal precautions in the fifth section of the questionnaire; this section comprised four questions, three of which were yes or no questions, while one question assessed the action that was taken after a needle prick or cut injury. The sixth section assessed respondents' training and development in HIV/AIDS; this domain had five questions, one of which was a Likert-scale question, while the remaining were yes or no questions. Knowledge about medical laws and ethics in the aspect of HIV comprised the last component of the questionnaire. This section had six Likert-scale questions with four response options; the scoring was in reverse order. A score $\leq 6$ was high, 7 - 12 moderate and 13 - 24 low.

\section{Data analysis}

The data were managed with the Statistical Package for Social Sciences (SPSS; IBM Corp., USA) software version 20, and the results presented in descriptive statistics.

\section{Ethical considerations}

Ethical permission for this study (reference number JUTH/DCS/ ADM/127/XXV/04, 20 February 2017) was obtained from JUTH.

\section{Results}

\section{Sociodemographic characteristics of respondents}

This research examined 99 respondents. More than half 58 $(58.6 \%)$ of the respondents were men. The age group $30-39$ years accounted for the highest number of participants, and the majority of the respondents $(46 ; 46.5 \%)$ had $\leq 5$ years of practice experience. Respondents with the most years of experience (30 - 39) constituted $4.0 \%$ of the population. Medical doctors constituted the highest proportion of the respondents $(85 ; 85.9 \%)$ while nurses represented $12.1 \%$. Four percent of the respondents were consultants. One-fifth of the respondents $(20 ; 20.2 \%)$ were in surgery, and another fifth in the obstetrics and gynaecology departments (Table 1).

\section{Attitude towards PLWHA}

The majority of the respondents' $(67 ; 67.7 \%)$ results showed that they had a negative attitude towards PLWHA.

\begin{tabular}{|c|c|}
\hline Sociodemographic characteristic & $n(\%) *$ \\
\hline \multicolumn{2}{|l|}{ Age } \\
\hline $20-29$ & $30(30.3)$ \\
\hline $30-39$ & $58(58.6)$ \\
\hline $40-49$ & $4(4.0)$ \\
\hline $50-59$ & $7(7.1)$ \\
\hline \multicolumn{2}{|l|}{ Sex } \\
\hline Male & $58(58.6)$ \\
\hline Female & $36(36.4)$ \\
\hline \multicolumn{2}{|l|}{ Years of experience } \\
\hline$\leq 5$ & $46(46.5)$ \\
\hline $6-10$ & $38(38.4)$ \\
\hline $11-19$ & $4(4.0)$ \\
\hline $20-29$ & $5(5.1)$ \\
\hline $30-39$ & $4(4.0)$ \\
\hline \multicolumn{2}{|l|}{ Profession } \\
\hline Medical doctor & $85(85.9)$ \\
\hline Nurse & $12(12.1)$ \\
\hline \multicolumn{2}{|l|}{ Rank } \\
\hline Consultant & $4(4.0)$ \\
\hline Resident doctor & $14(46.4)$ \\
\hline Medical officer & $32(24.2)$ \\
\hline Chief nursing officer & $6(6.1)$ \\
\hline Other & $12(12.1)$ \\
\hline \multicolumn{2}{|l|}{ Specialty } \\
\hline Orthopaedics & $10(10.1)$ \\
\hline Surgery & $20(20.2)$ \\
\hline Obstetrics and gynaecology & $20(20.2)$ \\
\hline Ear nose and throat & $7(7.1)$ \\
\hline Dental & $6(6.1)$ \\
\hline Other & $30(30.3)$ \\
\hline
\end{tabular}

\section{Attitude towards and practice of mandatory HIV testing}

More than half of the participants $(53 ; 53.5 \%)$ admitted that they had ever requested an HIV test in the process of providing medical care to their clients, but only $4.0 \%$ confirmed that they had declined to administer care because the client was HIV-positive. Meanwhile, $3.0 \%$ of the respondents reported that they had refused to provide medical care because the client had declined an HIV test. Just under half $(44.4 \%)$ of the participants admitted requesting an HIV test without the consent of the client, while $18.2 \%$ of the respondents had concealed the HIV test results from their clients (Table 2).

\section{Knowledge about HIV transmission}

The proportion of respondents whose knowledge about HIV transmission scored as high accounted for $46.5 \%$, and more than half $(51 ; 51.5 \%)$ had moderate knowledge of HIV transmission.

\section{Knowledge, practice and availability of consumables for universal precautions}

Forty-five $(45.5 \%)$ respondents had incurred a cut or a needle prick during surgical procedures; $20.2 \%$ of respondents had been counselled, tested and administered antiretroviral medicines within 72 hours, while $8.1 \%$ could not access antiretroviral medicines after 
counselling and testing. The majority of the respondents (79; 79.8\%) agreed that availability of equipment and consumables necessary for universal precautions was grossly inadequate (Table 3 ).

\section{Training and self-assessment}

The majority of the respondents (70; 70.7\%) had attended HIV/ AIDS prevention and care training, $71.7 \%$ felt that they had received sufficient information about HIV data confidentiality, and $76.8 \%$ believed that they were sufficiently knowledgeable about the psychosocial aspects of HIV/AIDS (Table 4).

\section{Legal and ethical issues around HIV/AIDS}

Only $12(12.1 \%)$ of the respondents were scored at a high level of knowledge about the medical laws and ethics around HIV/AIDS, the majority $(74 ; 74.7 \%)$ demonstrated moderate knowledge while $(13$; $13.1 \%)$ had low knowledge.

\section{Discussion}

The risk to medical personnel of occupationally acquiring HIV infection has been a subject of great concern worldwide since HIV/ AIDS was discovered. Today, this issue has a reciprocal dimension: the safety of either the patient or the surgeon may be at risk. For the practitioner, it has become easier to request the HIV sero-status of a patient, and so if the patient tests HIV-positive, extra precautionary measures are observed to prevent patient-to-surgeon transmission of HIV. In some cases, the testing of patient HIV sero-status is performed mandatorily, and the practitioner might, either subtly or openly, decline to offer medical care if the patient is HIV-positive. Patients in developing countries may be naive about their fundamental human rights, and often, the law does not protect them. By contrast, in the developed world, patients often ask to know the sero-status of their surgeon prior to receiving surgical care..$^{[5]}$

Controversial issues such as these require critical legal and ethical evaluation, especially in developing countries, where the consumables and equipment that are intended to promote the practice of universal precautions are seldom guaranteed.

The present study revealed that the demand by the healthcare practitioners for the results of patients' HIV tests preparatory to surgical intervention was high $(34 ; 34.3 \%)$; however, levels of refusal to conduct surgical procedures, due to either a client's HIV serostatus or refusal to take an HIV test, were quite low, at $4 \%$ and $3 \%$, respectively. This finding is, however, quite low compared with that of Mahendra et al. ${ }^{[6]}$ who found a mandatory HIV-test practice rate of 79\% among doctors. Furthermore, in India, Kurien et al. ${ }^{[7]}$ and Sheik and Porter ${ }^{[4]}$ have demonstrated high demand for HIV tests results prior to surgical procedures. Kurien et al. ${ }^{[7]}$ reported that $18 \%$ of the

Table 2. Responses on attitude to, and practice of, mandatory HIV testing

\begin{tabular}{|c|c|c|}
\hline \multirow[b]{2}{*}{ Question } & \multicolumn{2}{|c|}{ Response, \%* } \\
\hline & Yes & No \\
\hline Have you ever requested a patient HIV test in the process of rendering medical care? & 53.5 & 45.5 \\
\hline In surgical or invasive emergency, would you insist on an HIV test result before rendering intervention? & 34.3 & 61.6 \\
\hline Have you ever refused to provide medical care because a client is HIV-positive? & 4.0 & 94.9 \\
\hline Have you ever refused to render a surgical/invasive procedure because a patient refused an HIV test? & 3.0 & 96.0 \\
\hline Have you ever ordered an HIV test without the knowledge or consent of a patient? & 44.4 & 54.5 \\
\hline Have you ever ordered an HIV test without informing the client of his/her HIV test results? & 18.2 & 80.8 \\
\hline
\end{tabular}

Table 3. Responses on knowledge, practice and availability of consumables for universal precautions

\begin{tabular}{|c|c|c|}
\hline \multirow[b]{2}{*}{ Question } & \multicolumn{2}{|c|}{ Response, \% } \\
\hline & Yes & No \\
\hline Have you ever had a cut/needle prick during a surgical/invasive procedure? & 45.5 & 53.5 \\
\hline \multicolumn{3}{|l|}{ If yes, what happened afterwards? (\% of yes responses) } \\
\hline I was counselled, tested and given ARVs within 72 hours & 20.2 & na \\
\hline I was counselled, tested but couldn't accessed ARVs & 8.1 & na \\
\hline Wearing two pairs of gloves provides enhanced protection against HIV infection & 59.6 & 36.4 \\
\hline Consumables and equipment necessary for universal precautions are either not available or grossly inadequate. & 79.8 & 15.2 \\
\hline
\end{tabular}

\section{Table 4. Responses on training and self-assessment}

\begin{tabular}{|c|c|c|}
\hline \multirow[b]{2}{*}{ Question } & \multicolumn{2}{|c|}{ Response, \%* } \\
\hline & Yes & No \\
\hline Have you ever attended HIV prevention and care training? & 70.7 & 27.3 \\
\hline Do you know that HIV data must be kept confidential? & 71.7 & 18.2 \\
\hline Have you been trained on the social and psychological aspect of HIV/AIDS? & 76.8 & 9.1 \\
\hline Have you ever taken an HIV test yourself? & 88.9 & 9.1 \\
\hline Have you taken an HIV test yourself in the last year? & 56.6 & 42.4 \\
\hline
\end{tabular}


respondents in their study refused to administer medical care if a patient was HIV positive. In such a situation, patients may sue the doctor for damages, and have damages awarded, if there is an abuse of their rights, including the right to confidentiality. ${ }^{[8]}$ Furthermore, ordering an HIV test without the consent of the patient is unethical; it infringes on the patient's fundamental rights. The national guidelines for HIV/AIDS care among adults and adolescents in Nigeria explicitly stipulate the conditions for HIV testing, and these should be adhered to.

In our study, we found that 44 (44.4\%) of the participants admitted to ordering an HIV test without the knowledge and consent of the clients. Mandatory testing for HIV without informed consent denies patients the opportunity for pre- and post-test counselling, which are important aspects of the HIV/AIDS prevention programme. This is a violation of the rights to privacy, bodily integrity and freedom from degrading and inhuman treatment, all of which are guaranteed under chapter IV of the Nigerian Constitution. ${ }^{[9]}$

Furthermore, 18 (18.2\%) of the respondents admitted to requesting an HIV test without informing the client of the test result. Patients have the right to be educated about their health and medication use, including the right to informed consent. In some cases, the HIV status of a patient is made known to others without the consent of the infected person..$^{[9]}$ In some cases, employees seeking medical treatment at a hospital owned by their employer complained of unethical practices on the part of the hospital, which sent the results of their tests to their employers without themselves knowing the outcome of the test or even knowing they had been tested. ${ }^{[9]}$

Nigeria is a signatory to international charters on human rights; however, the rights to privacy and to social order, which includes the right to access adequate medical and health facilities, of PLWHA, are often deliberately and flagrantly violated. ${ }^{[8]}$ PLWHA struggle with internalised stigma (self-stigma), perceived stigma and enacted stigma (discrimination), and practitioners within the healthcare system itself - doctors, pharmacists, laboratory scientists and nurses responsible for the care and treatment of PLWHA - are prime agents of HIV-related stigma and discrimination. ${ }^{[10,11]}$ Practitioners must know that patients have the right to refuse treatment when any of their rights are violated. These rights are universal, indivisible, interdependent and interrelated. ${ }^{[2]}$

The Nigerian High Court's decision in Georgina Ahamefule v Imperial Hospital is a celebrated case; although critics have argued that the decision lacked an in-depth analysis, it was applauded as a victory for the rights of PLWHA. ${ }^{[12]}$ The plaintiff, Mrs. Georgina Ahamefule, an employee of Imperial Hospital, presented with signs and symptoms suspicious of HIV. Her blood sample was taken for an unspecified laboratory investigation without her consent, and tested positive for HIV. The plaintiff alleged that she was shocked and devastated by the news of her HIV results and the subsequent termination of her employment; she could not cope emotionally, and hence lost her pregnancy. The plaintiff claimed that she was humiliated, and that the purported termination of her employment due to her HIV status was unlawful and illegal; it constituted unfair discrimination contrary to the provisions of the African Charter on Human and People's Rights (African Charter). ${ }^{[13]}$

More importantly, the plaintiff claimed that subjecting her to HIV testing without prior informed consent amounted to unlawful battery, and that the failure to provide pre- and post-test counselling services constituted unlawful neglect of professional duty. Any approach to scale-up HIV testing and prevention programmes must be consistent with a respect for human rights. ${ }^{[12]}$ Mrs. Ahamefule further claimed that the denial of treatment by the defendants due to her HIV status constituted a deliberate violation of her right to health, as guaranteed under the African Charter and the International Covenant on Economic, Social and Cultural Rights. ${ }^{[14]}$

Sheik and Porter ${ }^{[4]}$ stated that surgeons performed mandatory tests out of fear of acquiring HIV infection from patients; although they believed the risk to be minimal, it nevertheless remains. Health professionals often perceive HIV transmission from a subjective perspective, in view of their personal safety, ${ }_{1}^{[4]}$ which is both irrational and unethical, without considering that the patient might also stand the risk of contracting HIV from an infected health professional. In Nigeria, there exists a lack of respect for patients' rights, and patients are not expected to question the actions of healthcare providers ${ }^{[9]}$ Many women attending antenatal programmes in Nigeria have reportedly been subjected to mandatory testing for HIV, contrary to their wishes. ${ }^{[9]}$ This is a violation of the human rights guaranteed under the Nigerian Constitution and the African Charter. However, the Nigerian government has taken various steps, including the establishment of the National Agency for the Control of AIDS, to curb the menace of $\mathrm{HIV}_{;}{ }^{[12]}$ it is also worthwhile to note that Nigeria has recently signed a new antidiscrimination bill into law that protects the rights and dignity of PLWHA. ${ }^{[15]}$

In this study, needle-stick injuries were recorded in 45 (45.5\%) of the respondents. This is fairly high, and it is most likely the result of the inadequate provision of equipment and consumables that was reported by $79.8 \%$ of the respondents. A contentious issue on the subject of universal precautions is the failure to envisage institutional failure of the health system to ensure continuous provision of essential consumables that would guarantee the provisions of universal precautions and infection-control practices. There is no justification for the Nigerian government or the healthcare system to demand strict adherence to the UDHR charter and universal precautions when each has failed in its responsibility to provide sustainable basic healthcare services. The rising cost of healthcare implies that for most African countries, implementing universal precautions is extremely impracticable. Even when the hands are protected with gloves, the eyes and nostrils may still be exposed to high risk from blood splashes, because face masks might not be considered a necessary commodity, owing to inadequate funding.

This study is extremely relevant at this time, as it illuminates the rationale behind the high number of requests for patient HIV testing before conducting surgical procedures. It firstly reveals the fact that these requests for HIV tests, with or without patient consent, are made as a result of practitioners' fear of contracting HIV infection, as the supply of equipment and consumables necessary for universal precautions is grossly inadequate. Secondly, it provides evidence for the need for educational intervention on issues relating to universal precautions and standard operating procedures, as well as medical laws and ethics and their application in HIV/AIDS care.

There are two major limitations to this study: the choice of only two hospitals for the study, and secondly, and more importantly, the two tertiary healthcare centres instead of a mix of both secondary and tertiary hospitals, is inadequate for the generalisation of the findings. Lastly, this study employed a quantitative design, which is limited in 
scope, where a mixed method (qualitative and quantitative design) would have strengthened the findings. This study recommends that a qualitative study be carried out to further explore the fundamental issues around mandatory HIV testing, its implications, including in terms of ethics and human rights, and the complexities associated with such practices.

\section{Conclusion}

The demand for mandatory HIV testing of patients preparatory to surgery was found to be high among participants in this study, in contravention of the Nigerian National Policy on Testing, which forbids mandatory testing as a violation of the rights to privacy, bodily integrity and freedom from degrading and inhuman treatment However, mandatory HIV testing had been used as a basis for refusal to conduct surgical procedures in only $3-4 \%$ of participants. Requests for HIV tests without informed consent abounded; in some cases, HIV tests had been done and clients were not informed of their test results. The lack of essential equipment and consumables necessary for universal precautions and standard operating procedures was pervasive, and is indicative of a failing health system. This deprives individuals of their rights to health and freedom; this is particularly worrisome when it occurs in tertiary health institutions that are designated as regional referral centres.

\section{Acknowledgements. None.}

Author contributions. BNJ conceived the idea, frame the title, wrote part of the introduction, methods and discussion. AMJ wrote the application for ethical permission and conducted data collation. BMA conducted data analysis and wrote the results section. AIY was involved in questionnaire design and data collation. DAD wrote part of the discussion and reviewed the manuscript. DNJ wrote part of the introduction and provided the background on legal and ethical issues. MLPD reviewed the methodology, manuscript and questionnaire design.

DNJ died at the time that we were collecting data for this study. Rest in peace.

\section{Funding. None.}

Conflicts of interest. None.
1. Nygren-Krug H. Health and Human Rights: A Historical Perspective. World Health Organization Press Release. Geneva: WHO, 2008. www.who.int/hhr (accessed 14 January 2013)

2. Centre for the Right to Health (CRH). HIV/AIDS and Human Rights in Nigeria: Background Paper for HIV/AIDS Policy Review in Nigeria. Lagos: CRH, 2003:5. https://hivhealthclearinghouse.unesco.org/sites/default/files/resources/ PNACX553.pdf (accessed 2 November 2018).

3. Thomas G. Mandatory HIV testing: Rights of patients vs rights of health workers? Indian J Med Ethics 2009;6(3):157. https://doi.org/10.20529/ijme.2009.050

4. Sheik K, Porter JDH. 'It's $100 \%$ for me': Hospital practitioners' perspectives on mandatory HIV testing. Indian J Med Ethics 2009;6(3):132-137. https://doi. org/10.20529/ijme.2009.044

5. American College of Surgeons. Statement on the Surgeon and HIV Infection. Chicago: ACS, 2004. www.facs.org/fellows-info/statements/st-13.html (accessed 14 January 2013).

6. Mahendra V, Gilborn L, George B, et al. Reducing AIDS-Related Stigma and Discrimination in Indian Hospitals. Horizons Final Report. New Delhi: Population Council, 2006.

7. Kurien $\mathrm{M}$, Thomas $\mathrm{K}$, Ahuja RC, et al. Screening for HIV infection by health professionals in India. Natl Med J India 2007;20(2):59-66.

8. Osime OC, Odigie DU. Surgeons and HIV/AIDS: Medico-legal considerations. JMBR 2006;5(1):51-57. https://doi.org/10.4314/jmbr.v5i1.10683

9. Durojaye E, Ayankogbe O. A rights-based approach to access to HIV treatment in Nigeria. Afr Hum Rights Law J 2005;5(2):287-307. www.ahrlj.up.ac.za/durojaye-dayankogbe-o (accessed 7 May 2018).

10. Joint United Nations Programme on HIV and AIDS. Report on the Global AIDS Epidemic. Geneva: UNAIDS, 2008:76-78.

11. Amoran OA. HIV-related stigmatising attitude and practice among health care workers in Northern Nigeria. J Infect Dis Immunity 2011;3(13):226-232.

12. Durojaye E. So sweet, so sour: A commentary on the Nigerian High Court's decision in Georgina Ahamefule v Imperial Hospital \& Another relating to the rights of persons living with HIV. Afr Hum Rights Law J 2013;13:464-480.

13. African Charter on Human and Peoples' Rights. OAU Doc CAB/LEG/67/3/Rev 5. Adopted by the OAU, 27 June 1981 (entered into force 21 October 1986).

14. International Covenant on Economic, Social and Cultural Rights. Adopted 16 December 1966; GA Res 2200 (XXI), UN Doc A/6316 (1966) 993 UNTS 3 (entered into force 3 January 1976).

15. Joint United Nations Programme on HIV and AIDS. Nigeria Passes Law to Stop Discrimination Related to HIV. Geneva: UNAIDS, 2015. http://www.unaids.org/ en/resources/presscentre/featurestories/2015/february/20150211_nigerialaw (accessed 7 May 2018).

Accepted 22 May 2018. 